\title{
EDUCAÇÃO AMBIENTAL E SABERES SOCIOAMBIENTAIS: EXPERIÊNCIAS COM OS VISITANTES DO PROJETO TAMAR DA ILHA DO PAPAGAIO, VITÓRIA - ES.
}

\author{
Lorena Moreira Fardim¹, Soler Gonzalez ${ }^{2}$
}

\begin{abstract}
RESUMO
Esse artigo é fruto de uma pesquisa realizada para a obtenção do grau de licenciatura em Ciências Biológicas. Nos movimentos da pesquisa chegamos à base do Tamar, na Ilha do Papagaio, emergindo algumas problematizações: como as práticas de educação ambiental do Tamar atravessam os cotidianos escolares? Quais são as singularidades dos grupos e as potencialidades das visitas? Os objetivos dessa pesquisa foram problematizar e acompanhar os movimentos de educações ambientais que acontecem na vida cotidiana com as visitas no Projeto Tamar. Nossas aproximações metodológicas se inspiram nas pesquisas com os cotidianos. Apostamos em educações ambientais como educação política, que se constituem a cada dia. Assim esse trabalho foi uma tentativa de nos aproximar das educações ambientais que acontecem no Tamar.
\end{abstract}

Palavras-chave: Educação ambiental; Projeto Tamar; Pesquisa com o cotidiano.

\begin{abstract}
This article is result of a survey conducted to obtain graduation degree in Biological Sciences. In the movements of the research we reached Tamar Project, in Ilha do Papagaio, and some problematizations emerged: how Tamar environmental education practices cross school everyday? What are the peculiarities of the groups of visitors and potential of visits? The objectives of this research were to problematize and track the movements of environmental educations that happen in everyday life with visits to Tamar Project. Our methodological approaches are inspired by research with everyday. We understand environmental educations as political education, which constitute every day. So this work was an attempt to approach the environmental educations that happen in Tamar.
\end{abstract}

Keywords: Environmental education; Tamar Project; Search with everyday.

\section{INTRODUÇÃO}

Esse artigo é fruto de uma pesquisa realizada em 2015 para a obtenção do grau de licenciatura em Ciências Biológicas na Universidade Federal do Espírito Santo. Nos movimentos da pesquisa chegamos à base do Tamar, na Ilha do Papagaio. Nessa "ilha"

\footnotetext{
1 Bacharela e Licenciada em Ciências Biológicas pela Universidade Federal do Espírito Santo UFES.

2 Doutor em Educação Ambiental pela Universidade Federal do Espírito Santo - UFES. Professor do Centro de Educação da Universidade Federal do Espírito Santo - UFES.
} 
encontramos os sujeitos praticantes dessa pesquisa, aqueles que fazem parte das visitas monitoradas no Tamar: estudantes, professoras, professores, moradores locais, monitores, funcionários da base do Tamar. Nos territórios de aprendizagens da Ilha do Papagaio encontramos estudantes e tartarugas.

Assim, surgem algumas problematizações: como as práticas de educação ambiental e os saberes socioambientais dos visitantes do Tamar atravessam os cotidianos escolares? Quais são as singularidades e saberes dos grupos que realizam as visitas monitoradas no Tamar? E quais são as potencialidades pedagógicas, políticas, éticas e socioambientais das atividades realizadas no Tamar?

Nesse sentido, os objetivos da pesquisa foram problematizar e acompanhar os movimentos e as potencialidades de educações ambientais que acontecem nas relações da vida cotidiana dos sujeitos praticantes, apostando numa política de narratividade das experiências com o vivido e das intensidades das educações ambientais que não se guardam em livros, leis e documentos oficiais... educações ambientais que escapam às normas pela potência das suas micro relações políticas e cotidianas.

Nossas apostas metodológicas se inspiram nas aproximações com os movimentos das pesquisas com os cotidianos, tendo como interlocutores teóricos e metodológicos os trabalhos de Marcos Reigota, Humberto Maturana, Nilda Alves (2001) e Carlos Eduardo Ferraço (2003). Os trabalhos de campo envolveram narrativas, experiências, conversas e fotografias nos diferentes espaçostempos e territórios do campo da pesquisa, envolvendo, estudantes, professoras/es, moradores locais, funcionários do parque e visitantes da Ilha do Papagaio.

Encontramos redes de saberes, tensões, poderes, instituições e pessoas que fizeram com que o nosso campo de pesquisa fosse complexo e rico. E nesses movimentos exercitamos educações ambientais que vão além das normas e das leis. Nessas travessias apostamos nas educações ambientais que se constituem nas micro relações, nas redes de conversação e no cotidiano. Na educação ambiental como educação política.

A partir do cotidiano e das experiências que vivemos no Tamar construímos essa pesquisa e trouxemos para esse trabalho as micro relações e as ecologias menores que se constituem a cada visita. As educações ambientais que se formam e se desenvolvem 
nesse espaço, que se mostrou um ambiente para crianças e jovens, para escolas públicas e particulares, instituições de Vitória e arredores.

Um espaço onde os professores/as levam seus alunos/as para trabalharem projetos que envolvem artes, biologia, literatura, geografia e tantas outras disciplinas, em um movimento em que o Tamar atravessa o cotidiano escolar e a escola atravessa o Tamar. E também um local com grande potencial pedagógico, político, ético e socioambiental. Assim esse trabalho foi uma tentativa de nos aproximar das educações ambientais que acontecem no cotidiano da base do Tamar na Ilha do Papagaio.

\section{ENCONTROS COM EDUCAÇÕES AMBIENTAIS COTIDIANAS}

Crise hídrica, desmatamento, aquecimento global, poluição, extinção de espécies e tantas outras mazelas que afetam o Brasil e o mundo são retratos do cenário em que vivemos hoje. Alguns desses problemas socioambientais surgiram há décadas e se estendem até a atualidade. Mas será que existe alguma maneira de acabar ou pelo menos amenizar essas mazelas?

\footnotetext{
Quanto mais rápido se incrementar a consciência ecológica mais potente ela será e, assim, nos levará a tomar medidas drásticas, que supõem dificuldades para muitos, mas que conservarão o espaço onde seres humanos possam viver. Do contrário, ou nos extinguimos ou nos transformamos estritamente em seres que vivem num mundo artificial, que será, então, o mundo natural. O que queremos? Porque a conservação é uma questão de desejo, de estética, de estar bem [...] (MATURANA, 2000).
}

Muitos desses assuntos são discutidos em conferências mundiais, onde representantes de diversos países se reúnem para debater sobre os principais problemas socioambientais que afetam o nosso planeta. Em 1972 ocorreu a Primeira Conferência Mundial de Meio Ambiente Humano em Estocolmo, na Suécia. Nesta conferência foi discutido que se devia educar os cidadãos e as cidadãs para a solução dos problemas ambientais.

Nesse momento começava a surgir o que convencionamos chamar de educação ambiental. Mas Reigota (2012) também nos lembra que mesmo antes dessas conferências mundiais ocorrerem, já existiam pessoas, grupos, ações, tensões, conflitos e práticas de educação ambiental. Depois dessas conferências, muitas outras ocorreram e algumas foram sediadas no Brasil. 
No Brasil, um dos primeiros movimentos na legislação em direção a educação ambiental foi a Lei $n^{\circ}$ 6.938, de 31 de agosto de 1981, que dispõe sobre a Política Nacional do Meio Ambiente e assegura o direito a educação ambiental em todos os níveis de ensino (BRASIL, 1981). Em 1999, foi elaborada a Política Nacional de Educação Ambiental, instituída no Brasil pela Lei n 9.795, de 27 de abril de 1999 e estabelece em seu primeiro artigo o que é educação ambiental:

Art. $1^{\circ}$ Entendem-se por educação ambiental os processos por meio dos quais o indivíduo e a coletividade constroem valores sociais, conhecimentos, habilidades, atitudes e competências voltadas para a conservação do meio ambiente, bem de uso comum do povo, essencial à sadia qualidade de vida e sua sustentabilidade (BRASIL, 1999).

Essa dimensão institucional e governamental $^{3}$ da educação ambiental que envolve as leis, normas, regras e políticas são imprescindíveis na nossa sociedade. As leis tem um papel de grande importância para regulamentar, controlar e tentar estabelecer ordem e igualdade de direitos e deveres para todos os cidadãos e cidadãs. Mas, percebemos certas discrepâncias entre o que as palavras escritas nesses documentos dizem com o que acontece na vida cotidiana, sendo que a política de narratividade dos documentos oficiais, expressa o que a educação ambiental deve ser, em uma visão macro, de cima para baixo.

E quando vamos até as pessoas, conversar com crianças, jovens, trabalhadores, comunidades tradicionais, encontramos outras narratividades que ecoam as leituras de mundos e as micro relações cotidianas. Micro não em um sentido de ser um conhecimento ou uma visão inferior, mas no sentido político, estético e libertário da vida cotidiana.

Tradicionalmente a educação ambiental era relacionada à proteção e conservação das espécies animais e vegetais (REIGOTA, 2012). A educação ambiental era vista como algo intimamente relacionado à Biologia e a Ecologia e dissociado de aspectos sociais e políticos.

A Biologia, Ecologia, preservação e conservação das espécies são sim uma parte importante da educação ambiental. Mas a educação ambiental é muito mais que isso.

\footnotetext{
3 Para ampliar as possibilidades no assunto recomendamos a leitura do artigo do professor pesquisador Rodrigo Barchi, intitulado “Educação Ambiental e (eco)governamentalidade”. Disponível em http://www.scielo.br/pdf/ciedu/v22n3/1516-7313-ciedu-22-03-0635.pdf. Acessado em 13/10/16.
} 
Educação ambiental também envolve aspectos sociais, políticos, culturais e econômicos. Reigota (2012, p. 13) defende que a educação ambiental é uma educação política:

Quando afirmamos e definimos a educação ambiental como educação política, estamos afirmando que o que deve ser considerado prioritariamente na educação ambiental é a análise das relações políticas, econômicas, sociais e culturais entre a humanidade e a natureza e as relações entre os seres humanos, visando a superação dos mecanismos de controle e de dominação que impedem a participação livre, consciente e democrática de todos.

A educação ambiental é por essência questionadora, crítica e criativa (REIGOTA, 2012). Faz com que questionemos a sociedade e o modo de vida que eu, que você e que nós temos hoje. Promove a formação de pessoas com senso crítico, que sabem opinar e refletir. E é por excelência criativa, tentando buscar novos meios para melhorar a relação das pessoas com tudo aquilo que as cerca.

Apostamos nas concepções de educação ambiental que considerem as experiências e os saberes praticados e vividos entre as relações das coletividades vivas e não vivas, potencializando as dimensões éticas, estéticas e políticas de uma cultura de aceitação do outro, como legítimo outro na convivência. Apostamos nas educações ambientais que se constituem no linguajar, no vivenciar, no experienciar e no conversar.

O conversar é um fluir na convivência, no entrelaçamento do linguajar e do emocionar. Ou seja, viver na convivência em coordenações de coordenações de fazeres e de emoções. Por isso é que digo que tudo o que é humano se constitui pela conversa, o fluxo de coordenações de fazeres e emoções. Quando alguém, por exemplo, aprende uma profissão, aprende em uma rede de conversações (MATURANA, 2004).

A educação ambiental, como educação política e ética também promove um encontro de ideias, culturas e opiniões. Para se vivenciar a educação ambiental, nessa perspectiva, devemos falar e exercitar a escuta do que o outro tem a dizer. $\mathrm{O}$ conhecimento, a reflexão e o saber podem vir de um artigo científico como também podem vir de uma conversa com uma criança sobre suas experiências.

Porque não aproveitar a experiência que têm os alunos de viver em áreas da cidade descuidadas pelo poder público para discutir, por exemplo, a poluição dos riachos e dos córregos e os baixos níveis de bem-estar das populações, os lixões e os riscos que oferecem à saúde das gentes? [...] Por que não estabelecer uma "intimidade" entre os saberes curriculares fundamentais aos alunos e a experiência social que eles têm como indivíduos? (FREIRE, 1996, p. 30)

Decidimos assim vivenciar os cotidianos dos estudantes, professores/as, funcionários do parque e das tartarugas marinhas que vivem no parque. Quais os efeitos 
desses encontros de mundos, saberes, emoções? Fomos ouvir e conversar com as crianças, jovens, professores, professoras e funcionários, aprendendo, sendo afetados e ficando emocionados com as tartarugas marinhas.

\section{MERGULHANDO NO TAMAR}

De acordo com o Instituto Chico Mendes da Biodiversidade (ICMBio), até o final da década de 70 não existia nenhum programa de conservação marinha no Brasil e as tartarugas já estavam incluídas em uma lista de espécies ameaçadas de extinção. Durante esse período, um grupo de estudantes de Oceanografia da Universidade Federal do Rio Grande do Sul, organizou expedições para áreas remotas, como Fernando de Noronha e Atol das Rocas. Nessas expedições os estudantes puderam verificar, nos cotidianos dos mares, praias e oceanos, a exploração dos ambientes marinhos, o roubo dos ovos das tartarugas e a sua matança.

Após as expedições, os estudantes organizaram relatórios sobre o que presenciaram e enviaram ao Instituto Brasileiro de Desenvolvimento Florestal (IBDF). Além dessa denúncia também existia certa pressão internacional nesse período. As tartarugas marinhas eram vistas como um recurso natural compartilhado e diversos países já tinham políticas e programas de pesquisa sobre o ecossistema marinho, enquanto o Brasil não tinha nenhum programa nessa área.

Diante dessa situação em 1980, o antigo IBDF, que mais tarde se transformaria no Instituto Brasileiro do Meio Ambiente e dos Recursos Naturais Renováveis (Ibama), criou o Projeto Tamar. O nome Tamar surgiu da combinação das sílabas iniciais das palavras tartaruga marinha. Essa abreviação era utilizada nas placas de metal que marcavam as tartarugas para estudos e se tornou também o nome do Projeto.

O objetivo inicial do Projeto Tamar era de proteger as tartarugas marinhas, mas à medida que o trabalho foi sendo realizado, percebeu-se que também era necessário apoiar as comunidades costeiras e fornecer suporte econômico para as famílias, pois muitos pescadores tiravam parte de seu sustento da caça de tartarugas. Mais uma vez, e assim como esta pesquisa, o campo de trabalho e de pesquisa interfere e atualiza as ações do pesquisador.

Nesse processo de construção e transformação do Projeto Tamar encontramos algumas similaridades com as transformações e visões de educação ambiental ao longo 
do tempo. Podemos ver que aquela educação ambiental, prescritiva, muitas vezes não é a educação ambiental do cotidiano. A educação ambiental não envolve apenas conservação e preservação, mas também envolve aspectos políticos, sociais e econômicos.

O Tamar teve que se reconstruir para atender as demandas das comunidades e para continuar com o seu objetivo de conservação das tartarugas marinhas. Assim como as educações ambientais se reconstroem no encontro com os seus sujeitos praticantes, no vivenciar, no cotidiano e nas conversações.

O projeto Tamar está presente atualmente em nove estados do Brasil e possui 25 bases ao longo da costa brasileira (TAMAR, 2015). No Espírito Santo os trabalhos do Tamar se concentram em seis regiões. A base do Tamar na Ilha do Papagaio em Vitória é a mais recente em solo capixaba (Figura 1). A inauguração da base ocorreu em novembro de 2012 e desde então a base vem recebendo visitantes capixabas e também de outros estados brasileiros. Há também visitas monitoradas direcionadas para escolas, universidades e grupos organizados. Apostamos neste trabalho em acompanhar os saberes socioambientais, experiências e as relações potencializadas pelas visitas monitoradas na Ilha do Papagaio e seus atravessamentos nos cotidianos escolares. 


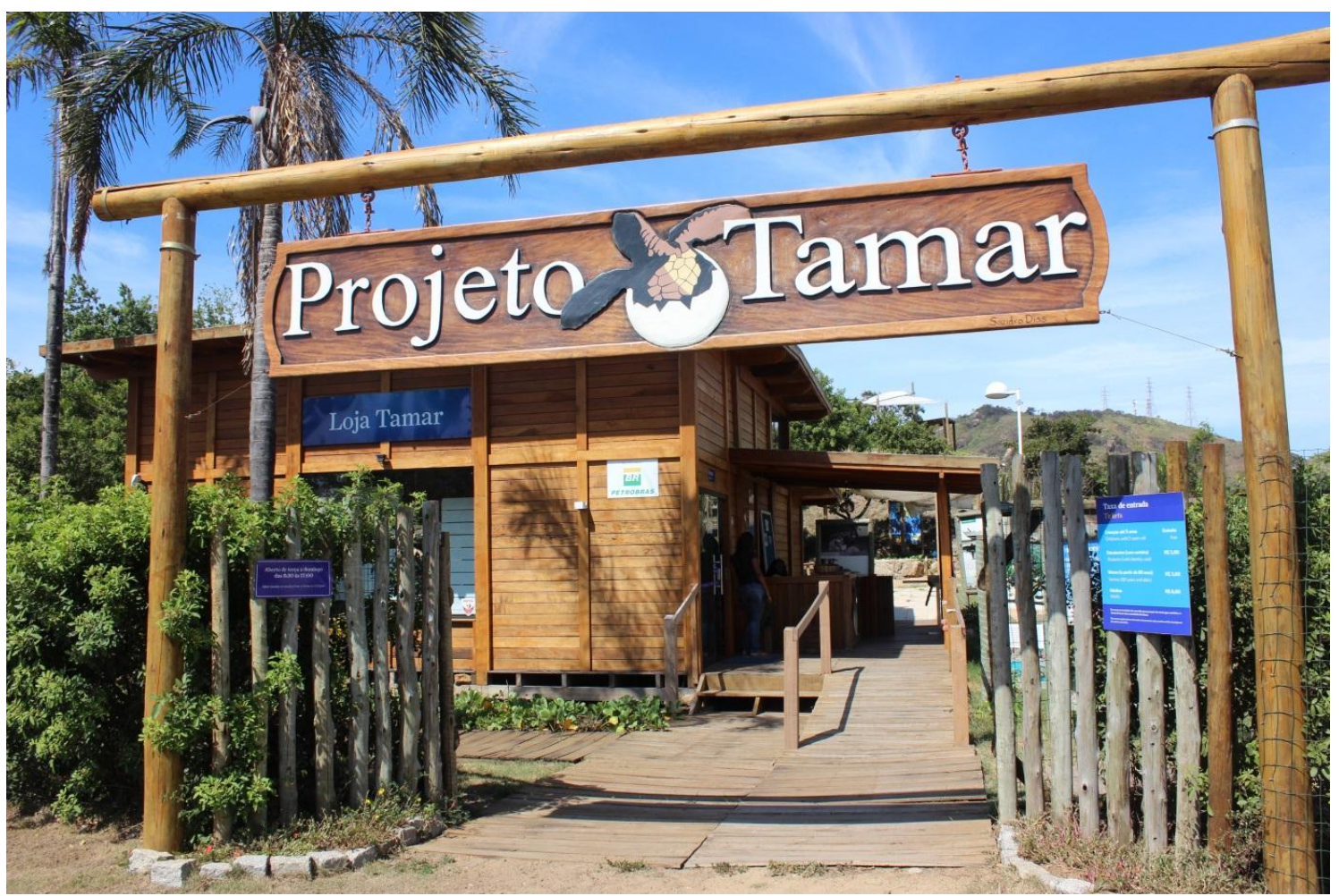

Figura 1. Base do Tamar na Ilha do Papagaio, Vitória - ES.

Fonte: Arquivo pessoal dos autores, 2015.

Quando chegamos à Ilha do Papagaio encontramos um ambiente muito diverso, dinâmico, com crianças, jovens, professores/as e comunidade se encontrando e conversando. Essa diversidade de experiências e vivências que todas essas pessoas (e instituições) trazem consigo fazem com que o campo da nossa pesquisa seja um campo complexo, com diferentes tensões, poderes, saberes e desejos se misturando em um mesmo local, o local da nossa pesquisa, a Ilha do Papagaio. Esse campo complexo também é um campo muito rico para problematizarmos as educações ambientais que habitam esse território de aprendizagens, desta forma, nos inspiramos metodologicamente nas pesquisas com os cotidianos e nas pesquisas narrativas, com o desejo de acompanhar a complexidade do campo da pesquisa.

\section{APROXIMAÇÕES E INSPIRAÇÕES METODOLÓGICAS COM VISITAS MONITORADAS NA ILHA DO PAPAGAIO}

$\mathrm{Na}$ Ilha do Papagaio, o nosso complexo campo de pesquisa, fomos à busca das educações ambientais que se constroem diariamente com as visitas monitoradas, com o desejo de problematizar aquelas educações ambientais que vão além das leis, as 
educações ambientais do vivenciar e do conviver. Aquelas educações ambientais que se constroem na relação com o outro, no convívio e no cotidiano.

A pesquisa com o cotidiano como proposto por Ferraço (2003) é a pesquisa do fazer junto. É a pesquisa em que precisamos estar mergulhados no cotidiano para pensar esse cotidiano. $\mathrm{Na}$ pesquisa com o cotidiano, pensar, classificar e estruturar metodologias antes de se estar inserido no cotidiano não faz muito sentido e pode ser uma tentativa de engessar a realidade. "De modo geral, uma metodologia de análise $a$ priori nega a possibilidade do “com”, “do fazer junto". Resulta em uma metodologia que antecede, que pensa antes o que poderá acontecer. Possível mas não passam de previsões, como as do tempo..." (FERRAÇO, 2003).

A fim de tentar não engessar essa realidade, nos inspiramos em alternativas metodológicas como as sugeridas por Nilda Alves para realizar a pesquisa com o cotidiano. Para Nilda Alves (2001) existem quatro movimentos necessários para o desenvolvimento desse tipo de pesquisa.

O primeiro deles é o que a pesquisadora denominou de sentimento do mundo, no qual é necessário que o pesquisador sinta o mundo e não somente o veja de longe, deixando-se mergulhar com todos os sentidos no seu campo de estudo (ALVES, 2003).

O segundo movimento foi denominado pela pesquisadora virar de ponta cabeça. $\mathrm{Na}$ ciência estamos acostumados a ter fortes bases teóricas para que possamos executar nosso trabalho. Nilda Alves (2001) defende que o que somos acostumados a chamar de base, na pesquisa com o cotidiano são na verdade limites, que nos permitem chegar somente até determinado ponto. A única base aceita na pesquisa com o cotidiano é o espaço/tempo daquele cotidiano a ser pesquisado. E assim ao invés de categorizar, analisar e dividir iremos multiplicar as teorias, os conceitos e os fatos, aumentando assim essa rede de múltiplos saberes.

O terceiro movimento foi denominado pela pesquisadora de beber em todas as fontes (ALVES, 2001). O cotidiano está repleto de diferentes, múltiplas e complexas relações. Para tentar compreender essa complexidade ou pelo menos chegar perto disso, o pesquisador precisa buscar diferentes fontes. Fontes essas que muitas vezes são ditas como não importantes ou comuns.

Ao quarto movimento Alves (2001) denominou narrar a vida e literaturizar a ciência. Com esse movimento a pesquisadora propõe uma nova maneira de escrever, 
para que as descobertas, fatos, problemas e questionamentos produzidos com a pesquisa com o cotidiano possam chegar a todas e todos, inclusive aos sujeitos praticantes que vivem e fazem esse cotidiano.

Nessa pesquisa os sujeitos praticantes (CERTEAU, 1994) e protagonistas da pesquisa são os estudantes dos mais variados níveis de ensino e de escolas públicas e particulares que visitam a Ilha do Papagaia e o Projeto Tamar: professoras(es) que levam os estudantes, moradores locais, grupos de visitantes e funcionários.

Nós acompanhamos os protagonistas dessa pesquisa e as suas visitas guiadas no Tamar durante o primeiro semestre do ano de 2015, mais especificamente a nossa vivencia no Tamar ocorreu dos meses de março a maio. Nesse período vivenciamos as redes de conversação tecidas nesse cotidiano e compartilhamos experiências.

É bom lembrar que o que vivenciamos com os protagonistas da nossa pesquisa é só uma pequena parte de suas vidas. Seus saberes vão muito além do que pudemos vivenciar no Tamar. Por mais que na pesquisa com o cotidiano façamos um mergulho no cotidiano que desejamos estudar, esse mergulho será limitado pelo tempo e espaço que nos colocamos. "Os estudos com o cotidiano [...] acontecem em meio às situações do dia a dia, por entre fragmentos das vidas vividas" (FERRAÇO, 2007, p. 81).

Nesse trabalho incluímos alguns trechos das conversas que foram registradas em um diário de campo e posteriormente foram transcritas. Nossos objetivos foram de "acompanhar processos e não representar um objeto" (GONZALEZ, 2013). Nós tentamos nos aproximar da realidade vivenciada pelos visitantes no Tamar, como ocorre esse processo, os motivos que levam eles a visitarem esse projeto, além disso, focamos nossa atenção para situações "corriqueiras" para tentar decifrar os saberes e significados que elas carregam.

Com as experiências na Ilha do Papagaio encontramos com os mais diversos grupos. Foram quinze diferentes grupos, sendo que desses quinze existiam treze diferentes instituições, envolvendo estudantes de instituições públicas e particulares, da educação infantil, do ensino fundamental e de projetos sociais. Projetos sociais que trabalhavam o esporte e a sustentabilidade com alunos/as de uma escola de tempo integral. Incluindo crianças, jovens e adultos que visitaram e que visitam o Tamar.

Um dos primeiros grupos que encontramos no Tamar foi uma creche particular. Esse grupo tinha aproximadamente dez alunos/as de três anos de idade. Em conversa 
com uma das professoras ela nos contou que a visita ao Tamar fazia parte de um projeto pedagógico que a creche estava desenvolvendo. Nesse projeto a creche leva alguns animais para a escola e também leva os alunos/as ao Tamar para eles verem as tartarugas. Depois da visita ao Tamar os estudantes desenvolverão atividades artísticas sobre o que eles viram no projeto.

Outra experiência que tivemos com a educação infantil no Tamar foi o encontro com um Centro Municipal de Educação Infantil (CMEI). As crianças desse grupo tinham de três a quatro anos. A professora nos contou que as crianças estão desenvolvendo na escola um projeto de literatura com o livro " $O$ ovo" e no final do livro eles descobrem que o ovo é um ovo de tartaruga. Isso foi o que motivou ela a trazer as crianças ao Tamar. A partir desse livro ela já trabalhou várias atividades com as crianças na escola, como fantoches, música e atividades de pesquisa na informática. Depois da visita ao Tamar ela pretende confeccionar junto com as crianças o livro " $O$ ovo" usando dobraduras e materiais de sucata.

A conversa com essa professora nos ajuda a problematizar como o Tamar atravessou o cotidiano dessa escola. Por meio de um projeto de literatura esses alunos/as chegaram ao Tamar. Por meio desses projetos eles puderam trabalhar em diferentes áreas do conhecimento como português, biologia, artes e informática. E também foi possível trabalhar diferentes atividades como música, pesquisa, leitura e desenhos.

Além de encontros com crianças da educação infantil, na nossa vivência também encontramos estudantes do ensino fundamental. Um desses grupos foi uma turma do quinto ano do ensino fundamental, de uma escola pública. A professora nos contou que a visita ao Tamar faz parte de um projeto que ela desenvolve na escola:

- Eu gostaria de saber o que trouxe vocês a realizar uma visita ao Tamar?

- Essa visita faz parte de um projeto que eu desenvolvo na escola. O projeto "Conhecendo as belezas do Espírito Santo”.

- E o que vocês fazem nesse projeto?

- Nesse projeto primeiro os alunos conhecem as praias do litoral do Espírito Santo e o projeto Tamar. Nesse primeiro momento os alunos realizam cinco paradas em praias do nosso litoral e no Tamar. Eles recebem uma folha e em cada parada eles precisam 
escrever o que viram, o que aprenderam e o que gostaram. Mais para ofinal do projeto a gente vai conhecer a região serrana.

- E qual é o objetivo desse projeto?

- O objetivo desse projeto é conhecer as diferenças geográficas do Espírito Santo e comparar as diferenças entre o litoral e as montanhas. Todo ano eu realizo algum projeto.

Além das escolas também encontramos outras instituições visitando o Tamar. Uma delas foi uma escolinha de esportes. Essa escolinha de esportes é um projeto da prefeitura, em que crianças com sete a doze anos são levadas a um clube para realizar atividades como natação, vôlei, basquete, futsal e remo. As crianças vão para o projeto no período da manhã e a tarde vão para a escola. O objetivo desse projeto é envolver crianças em situações de rua e além das atividades esportivas, muitas vezes o responsável pelas crianças as leva a exposições e atrações na cidade.

Acompanhamos outras turmas, mas devido à limitação da nossa pesquisa decidimos falar somente sobre esses grupos para mostrar a diversidade de pessoas e instituições que vão até ao Tamar, pelos mais variados motivos. A maioria das escolas levam os alunos/as ao Tamar porque estão desenvolvendo algum tipo de trabalho e/ou projeto sobre animais e meio ambiente e tem um objetivo claro ao levar seus alunos/as a esse espaço.

Poucas foram as conversas em que percebemos que os professores/as levavam seus alunos/as ao Tamar sem um objetivo definido. Não que isso seja ruim, pois só o fato de levar ao Tamar já proporciona experiências e saberes entre os visitantes. Apesar da variedade de instituições que visitam o Tamar pudemos perceber que escolas do ensino fundamental são as que mais procuram o projeto.

Outra característica marcante dos grupos é que a visita não é uma atividade isolada. A maioria dos grupos realiza algum tipo de atividade depois da visita. Os tipos de atividades mais comuns relatados foram projetos que trabalham temas como educação ambiental, meio ambiente e sustentabilidade. Depois da visita essa experiência é trabalhada nos projetos desenvolvidos pelas instituições por meio de diferentes atividades como, por exemplo, produção de desenhos, trabalhos escritos e painéis. Desta forma, as visitas e as práticas pedagógicas desenvolvidas nas escolas e projetos que levam suas crianças e adolescentes se atravessam. 


\section{NOS CAMINHOS DAS TARTARUGAS}

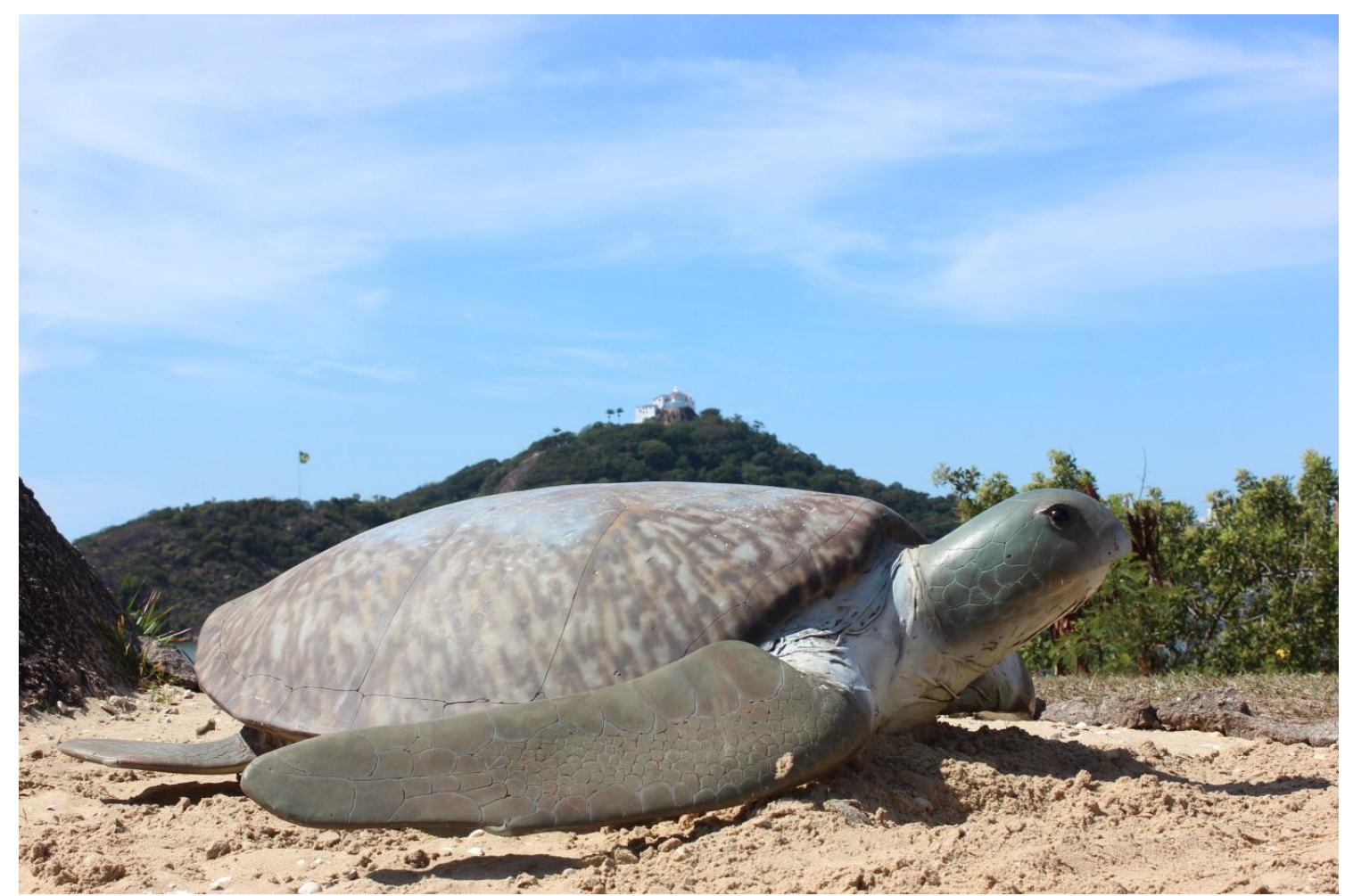

Figura 2. Um dos pontos de visita no Projeto Tamar. Réplica de uma tartaruga marinha com o Convento da Penha ao fundo.

Fonte: Arquivo pessoal dos autores, 2015.

Encontramos vários grupos e instituições nessa nossa vivência no Tamar. Tentamos mostrar os saberes dos visitantes e um pouco das sua experiências e vivências no Tamar, por meio de algumas conversas e problematizações. O primeiro ponto a ser visitado no Projeto é uma tenda onde os visitantes assistem um vídeo. Depois do vídeo os atendentes conversam um pouco com os visitantes sobre o que eles viram.

Depois do vídeo os alunos/as vão até um tanque com uma tartaruga verde juvenil. Esse encontro com a tartaruga é um momento de muita empolgação. Para muitos ali é a primeira vez que eles veem uma tartaruga. E independente da idade eles ficam muito animados. A euforia toma conta de todos e eles começam a conversar o que sabem e se mostrarem curiosos diante do que ainda não conhecem.

- Vocês sabem o que a tartaruga verde come? - O atendente questiona.

- A tartaruga verde come salada? - Questiona a criança de 3 anos. 
- Tipo isso! Ela come alga. Vocês sabem o que é alga?

- É uma coisa que cresce no mar, os peixes gostam de comer é é verde como grama. Responde o outro menino do grupo.

A narrativa desse menino nos faz problematizar como muitas vezes ignoramos o que eles têm a dizer, a contar e a narrar sem a sofisticação da escrita científica, mas com a verdade do conhecimento de uma criança, que associa, compara e explica o que é alga no seu linguajar: cresce no mar, peixe gosta de comer, verde como grama.

Essa narrativa nos remete a Freire (1996) que nos questiona porque não aproveitar as experiências dos estudantes? Eles têm sim muito a nos dizer e só temos que saber escutar e conversar. Para Freire "quem ensina aprende ao ensinar e quem aprende ensina ao aprender". É uma via de mão dupla!

O terceiro momento da visita é em uma área que possui réplicas das cinco espécies de tartarugas marinhas que ocorrem no Brasil. Nessa área os atendentes perguntam aos visitantes qual é o nome de cada tartaruga baseado no que eles viram no vídeo. Eles conversam sobre cada espécie, o que cada uma come e onde ocorrem no Brasil:

- Essa aqui é a tartaruga verde. Que é aquela que nós vimos no tanque. Quando ela se torna adulta ela se alimenta de algas. Vocês sabem o nome dessa tartaruga aqui?

- É a Olivia?

- É a Oliva. Ela gosta de comer camarão.

- Eu gosto de camarão tia!

- Eu também gosto de camarão. - Responde a atendente.

- E essa aqui vocês sabem o nome dela?

- É a grande!

- Isso! Essa aqui é a de couro ou gigante. Ela é a maior tartaruga marinha que existe hoje. Ela come água viva e desova nas praias de Regência aqui no nosso estado. E essa aqui é a cabeçuda. Vocês sabem por que ela tem essa cabeça grande?

- Por quê??

- Ela tem essa cabeça grande porque ela come alimentos duros, como por exemplo, caranguejo. E essa aqui é a de pente. Vocês sabem por que ela tem esse nome?

- Por que eles usavam ela pra fazer pente?! 
- Isso mesmo! No passado as pessoas usavam o casco dela pra fazer pente. Vocês sabem o que ela come?

- Não! O quê?

- Quem aqui já viu Bob Esponja?

- Eu! Eu! Eu! - As crianças sempre ficam eufóricas.

- Então no mar existe um bichinho que é uma esponja tipo o Bob Esponja. Ela gosta de comer esponja.

Depois da conversa os visitantes podem entrar na área e tocar as réplicas. Eles olham, tocam, possam para fotos e querem observar todos os detalhes. Os olhares curiosos são despertados para aquelas tartarugas...

Um próximo momento é quando os visitantes vão até o tanque barco. Esse ponto tem um tanque montado dentro de um barco e os visitantes podem ver uma tartaruga de pente macho, de dezoito anos, e três tartarugas cabeçudas de três anos. Nesse tanque o atendente fala um pouco sobre a maturidade sexual desses animais e a diferença entre machos e fêmeas.

Depois os visitantes chegam à seção de Material Biológico. Nessa seção eles podem ver materiais conservados como: ovos, crânios, filhotes de tartarugas. Também tem um pote com o lixo encontrado no trato gastrointestinal de uma tartaruga verde que morreu devido a ingestão de lixo. Os atendentes aproveitam para falar sobre a questão do lixo no ambiente marinho:

- Isso tudo é de verdade?

- É de verdade! Esses aqui são os ovos da tartaruga.

- Por que as tartaruguinhas estão dentro disso?

- É para conservar as tartarugas.

- Vocês mataram a tartaruguinha?

- Não! Encontramos essas tartarugas mortas no ninho.

- Mas porque elas morreram?

- Algumas não conseguem sair do ninho e acabam morrendo. Esses aqui são os crânios de algumas tartarugas. E isso aqui é o lixo que encontramos dentro de uma tartaruga que morreu por que comeu todo esse lixo.

- Nossa! Isso tudo?! Tadinha dela! 
- Por isso nos não podemos jogar lixo nas ruas e nas praias, porque o lixo vai para o mar a tartaruga come e morre.

- Eu não jogo lixo na rua tio!

No próximo momento os visitantes podem ver uma réplica de uma tartaruga já extinta, o Archelon. $\mathrm{O}$ atendente fala um pouco sobre as características dessa tartaruga, que era maior do que a maior tartaruga marinha que existe hoje. $\mathrm{O}$ último ponto da visita guiada é uma maquete representando a Cadeia Vitória - Trindade. Nesse ponto o atendente explica um pouco sobre a ilha de Trindade. Fala sobre a importância dessa ilha oceânica para as tartarugas e que nessa ilha desova a tartaruga verde.

Depois desse ponto os visitantes ficam livres para aproveitar a vista e desfrutar da Ilha do Papagaio. Ao final era praticamente unânime que todos gostavam da visita desde as crianças até os adultos. E quando questionados o que mais gostavam de ver na visita todos nos contavam que gostavam de ver as tartarugas. Eles também nos contavam o que eles descobriram com a visita ao Tamar e do que mais gostavam nessa experiência:

- Não pode jogar lixo no mar porque a tartaruga come o lixo e morre.

- Tem que cuidar do meio ambiente. Por que os animais podem comer o que a gente joga e eles morrem.

- Não pode jogar lixo no chão, pra tartaruga não morrer.

- Não pode pescar a tartaruga.

- Gostei de aprender o que as tartarugas comem.

- Eu aprendi sobre os tipos de tartaruga.

- Eu não sabia que existiam cinco espécies de tartarugas.

- Eu aprendi como socorrer uma tartaruga se ela ficar presa na rede.

- Existe mais de uma espécie de tartaruga.

$\mathrm{Na}$ maioria dos grupos percebemos que os visitantes focavam muito na questão do lixo quando conversávamos sobre a visita. Na seção de material biológico todos ficavam espantados ao ver a quantidade de lixo encontrada no interior de uma tartaruga. Além da questão do lixo, conversar um pouco mais sobre as tartarugas, o meio ambiente e as ameaças ao ambiente marinho, ver as diferentes espécies de tartarugas em 
diferentes estágios do seu ciclo de vida e estar em um ambiente tão próximo do mar causa uma sensibilização nos visitantes.

Os visitantes depois de realizarem uma visita guiada saem do Tamar falando em não jogar lixo na rua, proteger as tartarugas e proteger o mar. Defendemos nesse trabalho que educação ambiental é muito mais que discutir sobre proteção das espécies é uma educação política. Mas esses movimentos de sensibilização e desequilíbrio são fundamentais para a formação de sujeitos questionadores, criativos e participativos.

A educação ambiental como educação política é por princípio: questionadora das certezas absolutas e dogmáticas; é criativa, pois busca desenvolver metodologias e temáticas que possibilitem descobertas e vivências, é inovadora quando relaciona os conteúdos e as temáticas ambientais com a vida cotidiana e estimula o diálogo de conhecimentos científicos, étnicos e populares e diferentes manifestações artísticas; e crítica muito crítica, em relação aos discursos e as práticas que desconsideram a capacidade de discernimento e de intervenção das pessoas e dos grupos independentes e distantes dos dogmas políticos, religiosos, culturais e sociais e da falta de ética (REIGOTA, 2012, p. 15).

Essas visitas atravessam os cotidianos escolares sendo palco para novas discussões e práticas nas instituições. Na maioria dos grupos que fazem a visita ao Tamar essa prática não ocorre de maneira isolada. $\mathrm{O}$ que foi visto e conversado no Tamar é trabalhado pelas escolas e projetos nos seus cotidianos. Conversar, vivenciar, agir, escutar e refletir são ações fundamentais na educação ambiental.

$\mathrm{Na}$ experiência de viver as visitas e conversar com os sujeitos praticantes da nossa pesquisa, tivemos a oportunidade de nos aproximar das micro-relações de cada pessoa e de cada visita. Pudemos viver um pouco das educações ambientais que se constituem no cotidiano.

\section{POTENCIALIDADES DAS VISITAS AO TAMAR}

A nossa experiência no Tamar nos mostrou que grupos diversos realizam as visitas monitoradas do projeto. Grupos de diferentes idades, de diferentes instituições e diferentes regiões. Além disso, com os nossos encontros no Tamar percebemos que vários são os motivos que levam os responsáveis pelo grupo a escolher o Tamar como local de visitação. As visitas monitoradas do Tamar possuem um potencial pedagógico, político, ético e socioambiental. 
Várias são as atividades pedagógicas que podem ser desenvolvidas com uma visita guiada ao Tamar envolvendo diferentes temas e diferentes áreas do conhecimento. Nas nossas visitas encontramos aquela professora que a partir de uma atividade de leitura do livro "O ovo" decidiu levar os estudantes ao Tamar. A partir dessa atividade ela trabalhou atividades que envolviam biologia e artes. A visita guiada no Tamar tem um potencial pedagógico para trabalhar as áreas do conhecimento de maneira interdisciplinar.

A visita ao Tamar foi uma oportunidade de conversar sobre questões relacionadas a região litorânea capixaba. E essa pode ser uma oportunidade de se conversar sobre a pesca, a exploração de petróleo e a poluição marinha no nosso estado, por exemplo.

A discussão de temas na área da Biologia também leva muitos estudantes ao Tamar. Encontramos professores/as que estavam trabalhando com seus alunos/as temas como animais e meio ambiente. A visita proporciona práticas pedagógicas que envolvem temas como Ecologia, Zoologia, Biologia marinha e tantas outras áreas dentro da Biologia que podem ser exploradas nas conversas sobre as tartarugas, seu ciclo de vida e suas principais ameaças.

As artes também estiveram presentes nos nossos encontros no Tamar. Alguns professores/as nos contaram que pretendiam desenvolver atividades de desenhos e construção de painéis com sucatas depois da visita ao Tamar. Algumas professoras também trabalharam músicas que falavam sobre animais, antes da visita ao Tamar. Música, desenho, painéis, colagem e tantas outras expressões artísticas podem ser explorados com a visita.

Biologia, Artes, Geografia e tantas outras áreas do conhecimento podem ser discutidas na visita guiada do Tamar. Um conhecimento atravessando o outro, uma experiência atravessando a outra. O Tamar é um espaço para variadas discussões. É um espaço de educação não formal com grande potencialidade pedagógica, onde as educações ambientais se recriam e atravessam as disciplinas.

A Ilha do Papagaio é um importante espaço pedagógico não-formal na capital capixaba. Segundo Freire (1996) "ensinar não é transferir conhecimento, mas criar as possibilidades para a sua produção ou a sua construção". E a nossa experiência no 
Tamar nos mostrou as potencialidades éticas, socioambientais, pedagógicas e políticas, sendo que de fendemos nesse trabalho a educação ambiental como educação política:

[...] a educação ambiental deve ser entendida como educação política, no sentido de que ela reivindica e prepara os cidadãos e as cidadãs para exigir e construir uma sociedade com justiça social, cidadanias (nacional e planetária), autogestão e ética nas relações sociais com a natureza (REIGOTA, 2012, p. 14).

A visita ao Tamar é um território de aprendizagens que potencializa a sensibilização ambiental entre os visitantes. Estar naquele ambiente, ver as tartarugas, ver o lixo que foi ingerido por esses animais, ouvir as ameaças ao ambiente marinho e ouvir sobre o que posso fazer para ajudar a preservar, faz com que os visitantes saiam do Tamar sensibilizados. Muitos saem falando sobre não jogar lixo nas ruas, não jogar lixo nas praias, ajudar as tartarugas, preservar o meio ambiente.

Não estamos falando que a visita ao Tamar pode mudar completamente os hábitos de vida de uma pessoa ou vai fazer com que as crianças e jovens que visitam o Tamar saiam de lá pequenos ambientalistas. Até mesmo porque o objetivo da educação ambiental não é este. Mas a visita provoca certa sensibilização e reflexão nos visitantes. Essa visita pode ser um passo inicial para discussões e reflexões maiores. E esse é um dos objetivos da educação ambiental como educação política. E são essas discussões e reflexões que constroem e reconstroem as educações ambientais.

\begin{abstract}
A pretensão da educação ambiental em formar cidadãos e cidadãs críticos e participativos não é de transformá-los em ecologistas e/ou ambientalistas inseridos num partido ou num movimento, mas sim formar pessoas "em situação de exigir que os cientistas respondam às suas perguntas, se esforcem por tornar a 'informação' que possuem pertinente e utilizável, em suma, se dirijam a eles como a interlocutores de quem seu trabalho depende" (STENGERS, 2002, p. 195) (REIGOTA, 2007, p. 54).
\end{abstract}

Essa educação ambiental que também é uma educação política e que é criada nas micro relações e na conversação, permite ouvir aqueles que vêm das margens (REIGOTA, 2010), e tecer conversas com as crianças que visitam o Tamar é ouvir vozes daqueles que muitas vezes estão à margem.

\title{
CONSIDERAÇÕES
}

A nossa pesquisa foi uma tentativa de problematizar as práticas de educação ambiental e os saberes socioambientais dos visitantes do Tamar. Discutir questões como quais são as singularidades e saberes dos grupos que realizam as visitas monitoradas no 
Tamar; e quais são as potencialidades pedagógicas, políticas, éticas e socioambientais das atividades realizadas no Tamar.

As redes de conversação tecidas com os sujeitos praticantes dessa pesquisa nos fez construir esse trabalho junto com eles. Fomos surpreendidos pelos saberes das crianças e jovens. Que utilizando seu linguajar despido do rigor científico nos mostraram que as associações e comparações são uma boa maneira de aproximar o conhecimento que muitas vezes se coloca distante como algo mais próximo a realidade deles.

Defendemos a perspectiva da educação ambiental como educação política que se preocupa com as relações éticas, sociais e ambientais tecidas entre os sujeitos. A educação ambiental que se constrói no cotidiano, por meio das conversas, das experiências, dos saberes e das micro relações. Defendemos as educações ambientais...

Percebemos e destacamos as potencialidades pedagógicas, políticas, éticas e socioambientais do Tamar. O Tamar como um espaço para apreender, compartilhar e refletir. A visita como um momento para multiplicar as discussões e os trabalhos desenvolvidos nas escolas e também como um momento para produzir novas discussões e trabalhos nas escolas. A visita geralmente não é uma atividade isolada dos grupos que vem ao Tamar. Ela será trabalhada em atividades e projetos futuros pelas instituições que levam suas turmas ao Tamar.

O Tamar atravessam os cotidianos escolares e os cotidianos escolares atravessam o Tamar, aproximando os visitantes das situações, problemas e ameaças ao litoral capixaba, potencializando sensibilizações nos visitantes que podem ver, sentir, ouvir e falar sobre essas temáticas. Cada visitante traz a sua experiência, cada visitante constrói a sua educação ambiental.

\section{REFERÊNCIAS}

ALVES, N. Decifrando o pergaminho - o cotidiano das escolas nas lógicas das redes cotidianas. In: OLIVEIRA, I. B.; ALVES, N. (Orgs.). Pesquisa no/do cotidiano das escolas: sobre redes de saberes. Rio de Janeiro: DP\&A, p. 13-38, 2001.

. Sobre movimentos das pesquisas nos/dos/com os cotidianos. Teias, Rio de Janeiro, v. 4, n. 7-8, p. 1-8, 2003.

BRASIL. Política Nacional do Meio Ambiente. Lei $n^{\circ}$ 6.938. Brasília, DF, 1981. Disponível em: <http://www.planalto.gov.br/ccivil_03/leis/L6938.htm>. Acesso em: 29 de junho de 2015. 
Política Nacional de Educação Ambiental. Lei n 9.795. Brasília, DF, 1999. Disponível em: <http://www.planalto.gov.br/ccivil_03/leis/19795.htm>. Acesso em: 30 de junho de 2015.

CERTEAU, M. A. A invenção do cotidiano 1: as artes de fazer. Petrópolis: Vozes, 1994.

FERRAÇO, C. E. Eu, caçador de mim. In: Garcia, R. L. (org.). Método: pesquisa com o cotidiano. Rio de Janeiro: DP\&A, 2003.

95, 2007.

Pesquisa com o cotidiano. Educação \& sociedade, Campinas, v. 28, n. 98, p.73-

FREIRE, P. Pedagogia da autonomia: saberes necessários à prática educativa. São Paulo: Paz e Terra, Coleção Leitura, 1996.

GONZALEZ, S. Educação ambiental autopoiética com as práticas do bairro ilha das caieiras entre os manguezais e as escolas. 2013. Tese (Doutorado em Educação) Universidade Federal do Espírito Santo. Vitória, 2013.

INSTITUTO CHICO MENDES (ICMBio). Tartarugas marinhas. Brasília, DF. Disponível em: <http://www.icmbio.gov.br/portal/biodiversidade/centros-depesquisa/tartarugas-marinhas.html>. Acesso em: 03 de julho de 2015.

MATURANA, H. Um problema de desejo. 2000. Entrevista concedida a Omar Sarrás Jadue. Disponível em: <http://www.antroposmoderno.com/antroarticulo.php?id_articulo=845.> Acesso em: 18 de setembro de 2015.

. Entrevista: Humberto Maturana. Humanitates, Brasília, v. 1, n. 2, 2004. Uma publicação do Centro de Ciências de Educação e Humanidades (CCEH) da Universidade Católica de Brasília (UCB).

REIGOTA, M. O estado da arte da pesquisa em educação ambiental no Brasil. Pesquisa em Educação Ambiental, v. 2, n. 1, p. 33-66, 2007.

A contribuição política e pedagógica dos que vem das margens. Teias, v.11, n. 21, p.1-6, 2010.

O que é educação ambiental. $2^{\circ}$ ed. São Paulo: Brasiliense, 2012. (Coleção Primeiros Passos).

STENGERS, I. A invenção das ciências modernas. São Paulo: Ed. 34, 2002.

TAMAR. Disponível em: <http://www.tamar.org.br/>. Acesso em: 04 de julho de 2015. 